\title{
In situ split plus portal vein ligation (ISLT) - a salvage procedure following inefficient portal vein embolization to gain adequate future liver remnant volume prior to extended liver resection
}

Nadja Lehwald-Tywuschik ${ }^{1,2+}$, Sascha Vaghiri ${ }^{1,2+}$, Jan Schulte am Esch³, Salman Alaghmand', Yan Klosterkemper ${ }^{4}$, Lars Schimmöller ${ }^{4}$, Anja Lachenmayer ${ }^{5}$, Hany Ashmawy ${ }^{1,2}$, Andreas Krieg ${ }^{1,2}$, Stefan A. Topp ${ }^{6}$,

Alexander Rehders ${ }^{1,2}$ and Wolfram Trudo Knoefel ${ }^{1,2^{*}}$

\begin{abstract}
Background: Right extended liver resection is frequently required to achieve tumor-free margins. Portal venous embolization (PVE) of the prospective resected hepatic segments for conditioning segments II/III does not always induce adequate hypertrophy in segments II and III (future liver remnant volume (FLRV)) for extended rightresection. Here, we present the technique of in situ split dissection along segments II/III plus portal disruption to segments IV-VIII (ISLT) as a salvage procedure to overcome inadequate gain of FLRV after PVE.

Methods: In eight patients, FLRV was further pre-conditioned following failed PVE prior to hepatectomy (ISLTgroup). We compared FLRV changes in the ISLT group with patients receiving extended right hepatectomy following sufficient PVE (PVEres-group). Survival of the ISLT-group was compared to PVEres patients and PVE patients with insufficient FLRV gain or tumor progress who did not receive further surgery (PVEnores-group).

Results: Patient characteristics and surgical outcome were comparable in both groups. The mean FLRV-to-bodyweight ratio in the ISLT group was smaller than in the PVEres-group pre- and post-PVE. One intraoperative mortality due to a coronary infarction was observed for an ISLT patient. ISLT was successfully completed in the remaining seven ISLT patients. Liver function and 2-year survival of 50\% was comparable to patients with extended right hepatectomy after efficient PVE. Patients who received a PVE but who were not subsequently resected (PVEnores) demonstrated no survival beyond 4 months.

(Continued on next page)
\end{abstract}

\footnotetext{
* Correspondence: WolframTrudo.Knoefel@med.uni-duesseldorf.de

${ }^{\dagger}$ Nadja Lehwald-Tywuschik and Sascha Vaghiri contributed equally to this

work.

'Department of Surgery A, University Hospital Duesseldorf, Duesseldorf,

Germany

${ }^{2}$ Department of General, Visceral, Thorax and Pediatric

Surgery,Heinrich-Heine-University Hospital, Moorenstr. 5, 40225 Duesseldorf, Germany

Full list of author information is available at the end of the article
}

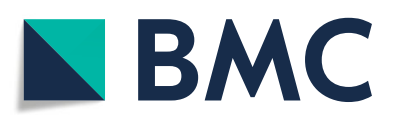

(- The Author(s). 2020 Open Access This article is licensed under a Creative Commons Attribution 4.0 International License, which permits use, sharing, adaptation, distribution and reproduction in any medium or format, as long as you give appropriate credit to the original author(s) and the source, provide a link to the Creative Commons licence, and indicate if changes were made. The images or other third party material in this article are included in the article's Creative Commons licence, unless indicated otherwise in a credit line to the material. If material is not included in the article's Creative Commons licence and your intended use is not permitted by statutory regulation or exceeds the permitted use, you will need to obtain permission directly from the copyright holder. To view a copy of this licence, visit http://creativecommons.org/licenses/by/4.0/. The Creative Commons Public Domain Dedication waiver (http://creativecommons.org/publicdomain/zero/1.0/) applies to the data made available in this article, unless otherwise stated in a credit line to the data. 
(Continued from previous page)

Conclusion: Despite extended embolization of segments I and IV-VIII, ISLT should be considered if hypertrophy was not adequate. Liver function and overall survival after ISLT was comparable to patients with trisectionectomy after efficient PVE.

Keywords: ALPPS, Liver resection, In situ split, Future liver remnant, Liver hypertrophy

\section{Background}

To date, surgical hepatic resection is the only curative treatment for patients with primary or secondary liver malignancies that can achieve complete tumor removal with tumor-free resection margins. However, the extend of liver resection remains a challenging factor that is limited by the size of the future liver remnant volume (FLRV). In the past, extended liver resection even with a sufficient FLRV has been feared due to the increased risk of postoperative liver failure [1-5]. In the past years, much progress has been made to induce hypertrophy in the FLRV before major hepatectomy [6]. Portal vein embolization (PVE) represents a well-established standard treatment to increase the FLRV by up to $40 \%$ [7-10]. However, it usually takes up to $6-8$ weeks after PVE to achieve an adequate liver volume for extended liver surgery; this interval can be as long as 150 days $[6,10]$. Moreover, it was reported that PVE has a failure rate of $20-30 \%$ as a result of tumor progression or inadequate hypertrophy $[8,11-14]$. In cases where PVE does not induce timely hypertrophy, the risk of tumor progression increases while awaiting sufficient FLRV to assure a safe extended liver resection $[12,13,15]$.

Recently, a new technique for hepatic resection called in situ split dissection along segments II and III plus portal disruption to hepatic segments IV to VIII (ISLT) also called ALPPS (Associating Liver Partition and Portal Vein Ligation for Staged Hepatectomy) has been introduced to induce an accelerated response of the FLRV within a reasonable period of time [16-22]. To date, only a few reports with small patient numbers exist that describe various ISLT procedures as a rescue strategy to overcome failed "classical" portal occlusion measures; these include interventional embolization and open surgical portal ligation concepts. The various ISLT techniques were developed to provide an alternative approach to induce adequate FLRV growth while preserving the perspective of a potential curative surgical strategy $[4,5,21,23-26]$. Here, we present a large single-center experience with ISLT as a salvage procedure for inefficient PVE of segments I/IV-VIII as a last measure to gain adequate FLRV.

\section{Methods}

\section{Patients}

Between January 2009 and January 2019, medical records of 48 consecutive patients scheduled for extended right hepatectomy (resection of hepatic segments I + IV to VIII) for primary or secondary liver malignancies were reviewed from the prospective clinical tumor registry, which is maintained by our oncological liver surgery program at the Department of General, Visceral, Thorax and Pediatric Surgery, University Hospital Duesseldorf, Germany. All of these patients were initially judged to be unresectable due to an insufficient FLRV (cumulative volume of segments II and III). Out of this cohort, 23 patients were scheduled for immediate ISLT (Fig. 1).

A further 25 patients underwent PVE followed by reevaluation of the FLRV before extended liver resection. Out of those 25 patients, extended right hepatectomy was performed in 12 patients after efficient PVE treatment and were categorized as PVEres-group (Fig. 1). PVE treatment was insufficient in 13 patients. Eight of these patients were scheduled for a salvage ISLT procedure to achieve an adequate FLRV, and were analyzed in this retrospective study as ISLT-group (Fig. 1). Five out of the 13 failed PVE patients were not eligible for further surgery due to insufficient FLRV gain or decisive tumor progression and were included as a separate group for analyses (PVEnores-group).

We compared survival time following the date that irresectability was determined after PVE in the PVEnores-group with survival after the last scheduled hepatic surgical intervention in the other two patient cohorts in this study. Further patient characteristics and surgical outcome were compared between the groups.

All patients with locally advanced liver malignancies were discussed and reviewed by a multidisciplinary tumor board including gastroenterologists, surgeons, radiation oncologists, pathologists and radiologists. This study was approved by the local institutional review board (Heinrich Heine University, Duesseldorf, Germany; study-no.: 2018-258-KFogU). All procedures performed in this study were in accordance with the ethical standards in the 1964 Declaration of Helsinki and its later amendments. Informed consent was waived because no data regarding the cases were disclosed.

The following parameters were obtained: patients characteristics including gender, age, ASA (American Society of Anesthesiologists) score, BMI (body mass index) and diabetes, oncological characteristics including tumor type, TNM stage, grading, R-status and neoadjuvant chemotherapy as well as surgical characteristics 


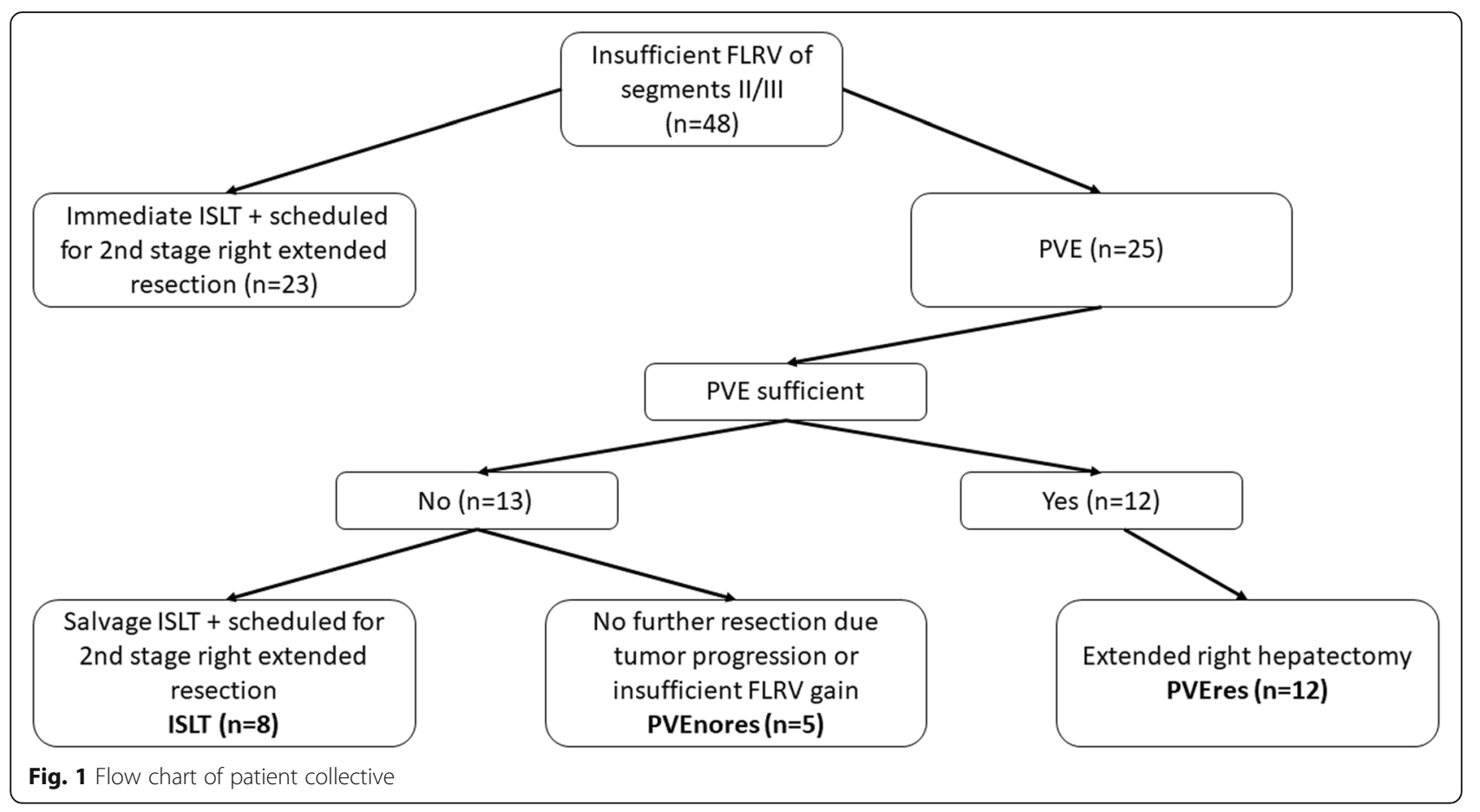

including hospital stay, morbidity and postoperative 90day mortality rates, survival, postoperative liver function and radiological data with volume gain of FLRV. Postoperative complications were classified I-IV according to the Clavien-Dindo classification [27].

\section{Hepatic volumetric assessments and portal vein embolization}

Patients underwent routine staging by using preoperative helical computed tomography (CT) scanning of the chest, abdomen, and pelvis. Initial total liver volumes (TLV) that excluded tumor volume (TV) and the FLRV were estimated at time of indication for hepatic resection by CT. Measurements were performed manually with respect to the hepatic segmentation based on the distribution of the portal pedicles and the location of the hepatic veins (Couinaud terminology) as previously described [21, 28]. From week 2 post PVE, differential absolute, relative and daily gains of the FLRV post-PVE were calculated in 2-3 weeks intervals to measure the change in hepatic volume: before PVE, after PVE and before resection. Patients after ISLT received CT volumetry every week.

Two methods for FLRV evaluation extrapolated from liver transplantation literature were applied to evaluate the sufficiency of the FLRV prior hepatic resection. Those are a) the ratio of FLRV to total liver volume and b) the ratio of FLRV to body weight (FLRVbw). In our study, we utilized method b) for determing the threshold of liver volume for resectability to exclude a phenomenon possible in method a) which is comparing parts of normal liver parenchyma to others compromised by biliary or vascular obstruction, by portal vein embolization or disturbance in measurement due to tumor volume as also discussed elsewere [29]. Extrapolating from living-donor liver transplantation, we hypothesized that FLRVbw more accurately assesses the functional limit of hepatectomy. For the FLRVbw, a ratio of of 0.4 to 0.5 was determined to be sufficient $[29,30]$. For extensive hepatic resection surgery as performed in this study, we set a rather conservative threshold of 0.5 for volumetric resectability in non-cirrotic patients as proposed also by others [30].

For PVE, a transileocolic portal venous approach was used. After visualization of the portal venous tree, histoacryl or polyvinyl alcohol particles were applied to occlude portovenous branches to liver segments I/IV-VIII as previously described [21]. After the hypertrophy period, an extended right hepatectomy was performed.

\section{Surgical technique}

The surgical technique for ISLT was performed as previously described [21]. In brief, for the ISLT procedure in stage 1 , the right portal vein was divided, whereas the right hepatic artery and right bile duct were identified and marked with a vessel loop for later transection during stage 2. After complete liver mobilization and transection of all retrohepatic veins, the liver parenchyma between segments II/III and I/IV-VIII was transected by using a cavitron ultrasonic surgical aspirator $\left(\mathrm{CUSA}^{\oplus}\right.$, Valleylab, Boulder,Colorado/USA) [21]. In stage 2, the 
right hepatic artery and right bile duct were transected and the resected liver was removed.

\section{Posthepatectomy liver failure}

Posthepatectomy liver failure (PHLV) was defined as the impaired ability of the liver to maintain its synthetic, excretory, and detoxifying functions, which was characterized by an increased international normalized ratio (INR) and concomitant hyperbilirubinemia according to the normal range of cut-off labels of our local laboratory on or after postoperative day (POD) 5 [31]. When INR or bilirubin were already increased preoperatively, PHLF was defined by increased values on or after POD 5 compared to the values of the previous day as previously described [31].

\section{Statistics}

All data were retrospectively collected and transferred into a database. Statistical analysis and graphing were performed using MS Excel and JMP 14.1 from SAS Institute Inc., Cary, USA. All results are expressed as mean \pm standard deviation. Statistical significance was determined by Student's t test and Chi-Square test. Survival curves significance was defined as ${ }^{*} p<0.05$. ${ }^{* *} p<$ 0.01 . The Kaplan-Meier method was used to estimate survival curves.

\section{Results}

\section{Patient characteristics}

Median age within PVEres and ISLT groups overall was 67 years and was comparable among these two cohorts (PVEres range: 44-81; ISLT range: $49-81$ years, $p=0.92$ ) (Table 1). In the ISLT group was $62.5 \%$ male [5] and $37.5 \%$ female [3] patients. The PVEres group included seven male $(58.3 \%)$ and five $(41.7 \%)$ female patients $(p=$ $0.85)$. ASA score $(p=0.12)$, BMI $(p=0.73)$ and diabetes $(p=0.49)$ were equally distributed between the study groups.

\section{Surgical characteristics and outcome}

There was no significant difference between the PVEres and the ISLT groups regarding mean hospital stay $(36.3$ days $+/-28.2$ vs. 30 days $+/-28.9 ; p=0.63$; Table 1 ). Complication were classified according to the DindoClavien classification [27]. There were no significant differences in minor or major postoperative complications between the ISLT and the PVEres group $(p=0.49)$. Four patients $(33 \%)$ in the PVEres group and one patient (13\%) in the ISLT group had an uneventful postoperative course without any minor or major complication. Minor complications (grade I-IIIa) related to resection occurred in two patients (17\%) and one patient (13\%) respectively. This included two wound infections and two patients with cholangitis. Major complications (grade IIIb-IVb)
Table 1 Patient and surgical characteristics comparing ISLT $(n=8)$ and PVEres $(n=12)$ group

\begin{tabular}{|c|c|c|c|}
\hline & PVEres & $I S L T$ & $p$-value \\
\hline & $\boldsymbol{n}=12$ & $\boldsymbol{n}=8$ & \\
\hline \multicolumn{4}{|l|}{ Patient characteristics } \\
\hline Age years (mean $\pm S D)$ & $67.5 \pm 11.2$ & $67 \pm 9.8$ & 0.92 \\
\hline Gender n (\%) & & & 0.85 \\
\hline Male & $7(58.3)$ & $5(62.5)$ & \\
\hline Female & $5(41.7)$ & $3(37.5)$ & \\
\hline ASA score $n(\%)$ & & & 0.12 \\
\hline 2 & $6(75)$ & $2(33.3)$ & \\
\hline 3 & $2(25)$ & $4(66.7)$ & \\
\hline BMI (mean + SD) & $26.5 \pm 3.7$ & $27.1 \pm 4.2$ & 0.73 \\
\hline Diabetes n (\%) & & & 0.49 \\
\hline Yes & $3(25)$ & $1(12.5)$ & \\
\hline No & $9(75)$ & $7(87.5)$ & \\
\hline \multicolumn{4}{|c|}{$\underline{\text { Surgical characteristics and early outcome }}$} \\
\hline $\begin{array}{l}\text { Hospital stay (d) } \\
\text { (median + SD) }\end{array}$ & $36.3 \pm 28.2$ & $30.0 \pm 28.9$ & 0.63 \\
\hline $\begin{array}{l}\text { Morbidity (Dindo/Clavien) } \\
n(\%)\end{array}$ & & & 0.49 \\
\hline no complication & $4(33.3)$ & $1(12.5)$ & \\
\hline |-IIIa & $2(16.7)$ & $112.5)$ & \\
\hline IIIb-IVb & $6(50)$ & $6(75)$ & \\
\hline Postop 90-day mortality n (\%) & $3(25)$ & $2(25)$ & 1 \\
\hline \multicolumn{4}{|c|}{$\begin{array}{l}\text { ASA American Society of Anesthesiologists, BMI body mass index, CCC } \\
\text { cholangiocellular carcinoma, CRLM colorectal liver metastasis, } d \text { days, } H C C \\
\text { hepatocellular carcinoma, ISLT patients with in situ split transection along } \\
\text { segments II and III plus portal ligation to hepatic segments IV to VIII, } R C L M \\
\text { renal cell carcinoma liver metastasis, } N E T \text { neuroendocrine tumor, } N \text { node, } M \\
\text { metastases, PVEres extended right hepatectomy promptly following sufficient } \\
\text { PVE, SD standard deviation, } T \text { tumor }\end{array}$} \\
\hline
\end{tabular}

occured in six patients in each group (50\% versus $75 \%$ respectively) (Table 1). Three PVEres-patients (25\%) and two patients after ISLT (25\%) had postoperative bile leaks. Posthepatectomy liver failure with increased INR or hyperbilirubinemia on or after postoperative day 5 occurred in three PVEres patients (25\%) and one ISLT patient (13\%) respectively. Two patients (17\%) in the PVEres group and one patient (13\%) in the ISLT group developed temporary renal failure. One failed hepaticojejunostomy, which needed revision surgery, and one acute respiratory distress syndrome occurred in the ISLT group. In the PVEres group, one small-bowel perforation with intestinal fistula and one case of postoperative bleeding occurred.

The 90-day mortality rate following extended right resection (stage 2 in the ISLT-group) was $14.3 \%$ in the ISLT-group ( $n=1 / 7$; data not shown) and $25 \%$ in the PVEres-group (3/12). Overall 90-day mortality subsequent to the last scheduled resection-concept surgery (stage 1 or 2 ) was $25 \%$ in both groups (PVEres: $3 / 12$; 
ISLT: $2 / 8 ; p=1$; Table 2). For the ISLT group, one patient died during the split procedure due to a fatal coronary infarction and one patient developed a myocardial infarction on day 7 following resection-completion surgery with lethal outcome. In the PVEres group, two

Table 2 Oncological characteristics comparing ISLT $(n=8)$ and PVEres $(n=12)$ group

\begin{tabular}{|c|c|c|c|}
\hline & PVEres & $I S L T$ & $p$-value \\
\hline & $\boldsymbol{n}=12$ & $\boldsymbol{n}=8$ & \\
\hline \multicolumn{4}{|l|}{ Oncological characteristics } \\
\hline Tumor Type n (\%) & & & 0.7 \\
\hline CRLM & $3(25)$ & $2(25)$ & \\
\hline RCCLM & 0 & $1(12.5)$ & \\
\hline $\mathrm{HCC}$ & $3(25)$ & $2(25)$ & \\
\hline CCC & $5(41.7)$ & $3(37.5)$ & \\
\hline NET & $1(8.3)$ & 0 & \\
\hline \multicolumn{4}{|l|}{ TNM stage n (\%) } \\
\hline T-stage & & & 0.88 \\
\hline 1 & $2(16.7)$ & $2(28.6)$ & \\
\hline 2 & $2(16.7)$ & $1(14.3)$ & \\
\hline 3 & $7(58.3)$ & $3(42.9)$ & \\
\hline 4 & $1(8.3)$ & $1(14.3)$ & \\
\hline N-stage n (\%) & & & 0.31 \\
\hline 0 & $7(58.3)$ & $2(25)$ & \\
\hline 1 & $4(33.3)$ & $3(37.5)$ & \\
\hline 2 & 0 & $1(12.5)$ & \\
\hline Nx & $1(8.3)$ & $2(25)$ & \\
\hline M-stage n (\%) & & & 0.21 \\
\hline 0 & $7(58.3)$ & $2(25)$ & \\
\hline 1 & $5(41.7)$ & $5(62.5)$ & \\
\hline Mx & 0 & $1(12.5)$ & \\
\hline Grading n (\%) & & & 0.2 \\
\hline G2 & $8(66.7)$ & $8(100)$ & \\
\hline G3 & $3(25)$ & 0 & \\
\hline Gx & $1(8.3)$ & 0 & \\
\hline Neoadjuvant chemotherapy $n(\%)$ & & & 1 \\
\hline Yes & $3(25)$ & $2(25)$ & \\
\hline No & $9(75)$ & $6(75)$ & \\
\hline R-status n (\%) & & & 0.34 \\
\hline RO & $11(91.7)$ & $7(87.5)$ & \\
\hline R1 & $1(8.3)$ & 0 & \\
\hline $\mathrm{Rx}$ & 0 & $1(12.5)$ & \\
\hline Number of lesions (mean + SD) & $2+1.9$ & $4 \pm 4.6$ & 0.36 \\
\hline $\begin{array}{l}\text { Maximum tumor diameter } \\
(\text { mean }+S D)\end{array}$ & $80.5 \pm 47.1$ & $66.3 \pm 27.7$ & 0.51 \\
\hline
\end{tabular}

$d$ days, ISLT patients with in situ split transection along segments II and III plus portal disruption to hepatic segments IV to VIII, PVEres extended right hepatectomy promptly following sufficient PVE, SD standard deviation patients died from septic multi organ failure. One patient died as a result of postoperative liver failure. However, there were no significant differences among groups regarding major complications $(p=0.49)$ or regarding the 90-day mortality (Table 1).

\section{Oncological characteristics}

Diagnosis for extended right hepatectomy showed various tumor types with no statistical difference in our two groups (Table 2). Likewise, neither TNM classification nor tumor grading caused a significant difference between the study groups. 25\% of patients (PVEres: 3 ; ISLT: 2) received neoadjuvant radiochemotherapy ( $p=$ 1). Local R0 (margin-free) resection could be achieved in 92\% (PVEres) and 88\% (ISLT) of the resected patients $(p=0.34)$. The mean number of liver lesions was 2.4 for the PVEres group compared to 4 in the ISLT group with no statistical difference. The maximum tumor diameter ranged $31-115 \mathrm{~mm}$ in the ISLT group compared to 14$180 \mathrm{~mm}$ in the PVEres group with no statistical difference (Table 2).

\section{Growth of FLRV following PVE +/- ISLT}

The mean initial FLRV prior to PVE was $276 \mathrm{ml} \pm 69$ in the PVEres group versus $346 \mathrm{ml} \pm 86$ in the ISLT group (Fig. 2a). After PVE treatment, the PVEres patients demonstrated a significant mean increase of $428 \mathrm{ml} \pm 140$ compared to ISLT patients with $333 \mathrm{ml} \pm 86$. However, seven of the patients who showed an insufficient hypertrophy of the FLRV and who then received a rescue split procedure revealed a significant 2 -fold mean increase in liver growth (from $333 \mathrm{ml} \pm 86$ to $621 \mathrm{ml} \pm 388$ ) before second-stage surgery (Fig. $2 \mathrm{a}$ ). This effect was resembled in the \% to body weight ratio for FLRV (Fig. 2b). The mean FLRV to body weight ratio (FLRVbw) in the ISLT group was smaller before PVE $(0.35+/-0.09 \%)$ and post PVE $(0.42+/-0.08 \%)$ compared to the PVEres-group $(0.49+/-0.17 \%$ and $0.67+/-0.05 \%)$ (Fig. 2b). For extensive hepatic resection surgery as performed in this study, we adopted a rather conservative threshold of 0.5 for volumetric resectability in non-cirrotic patients as previously described [30]. Post PVE or post split, we accepted a FLRVbw of 0.4 if an increase in FLRV of at least $20 \%$ as a sign of adequate regenerative response was achieved. In seven patients, ISLT was successfully completed with a mean FLRVbw of $0.81+/-0.09 \%$ receiving a completion of the extended right hepatectomy.

PVEnores patients $(n=5)$ demonstrated a slower growth of the FLRV compared to PVEres patients $(n=$ 12) (Suppl. Fig. 1A and B). Four of these patients (preISLT-era of our hepatic resection program) demonstrated inadequate liver growth with an insufficient FLRV. One patient, however, showed sufficient FLRV hypertrophy, but experienced significant tumor progress 


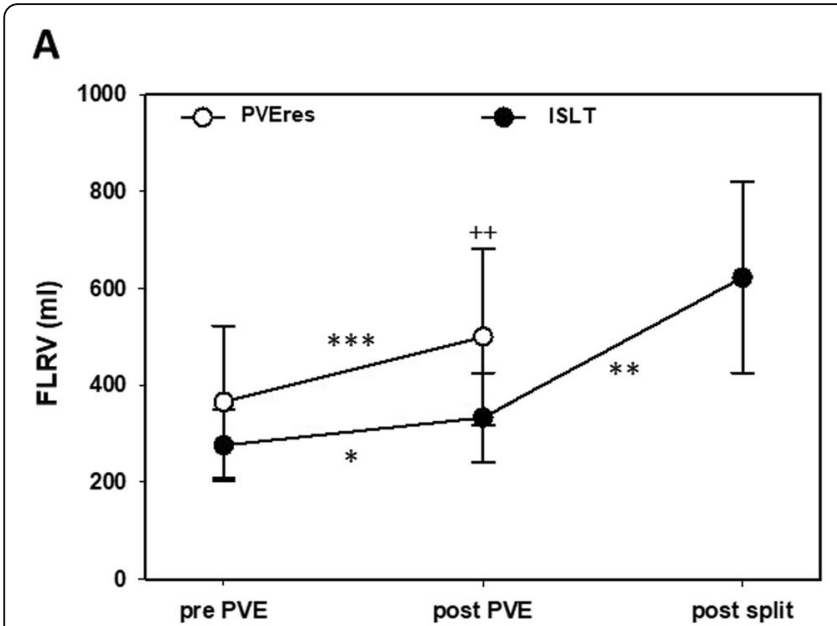

B

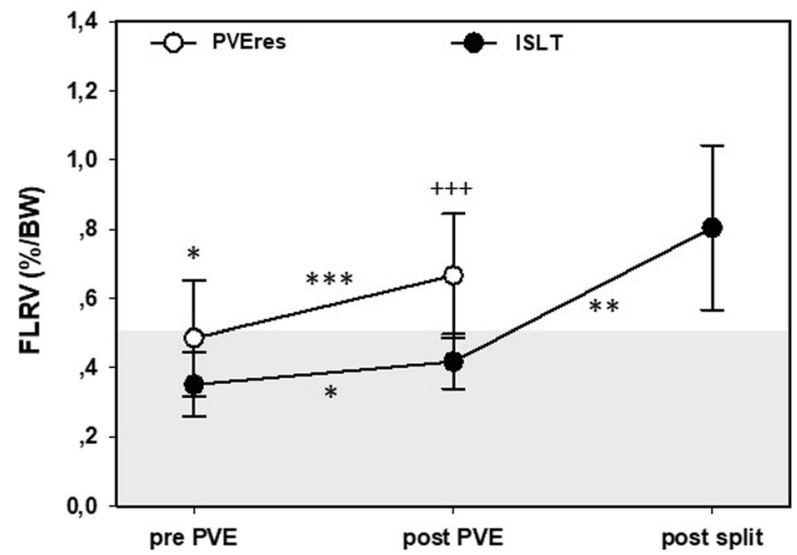

Fig. 2 a. ISLT (PVE + in situ split + resection) patients demonstrated a significant increase in FLRV post split. b. Increase in FLRV to bodyweight ratio post split for ISLT group. The dotted line indicates the critical FLR to bodyweight ratio of 0.5 . BW: body weight. FLRV: future liver remnant volume. ml: milliliter. ${ }^{*} p<0.05 ;{ }^{* *} p<0.01$

with peritoneal carcinomatosis as detected during surgical exploration.

\section{Survival analysis and liver function}

With a median follow up of 84.2 months $(9.2-132.5$ months) overall survival subsequent to the last scheduled hepatic resection-concept surgery was comparable between the ISLT $(n=8)$ and the PVEres group $(\mathrm{n}=12)$ with a 2 -year survival of 50 and $45.5 \%$ respectively $(p=0.8)$ (Fig. 3a). This is despite conservative data presentation and interpretation with inclusion of the one stage 1 intraoperative mortality in the ISLT group latter due to fatal cardiac infarction. Survival analyses revealed a strong survival benefit for the ISLT group when compared to the PVEnores

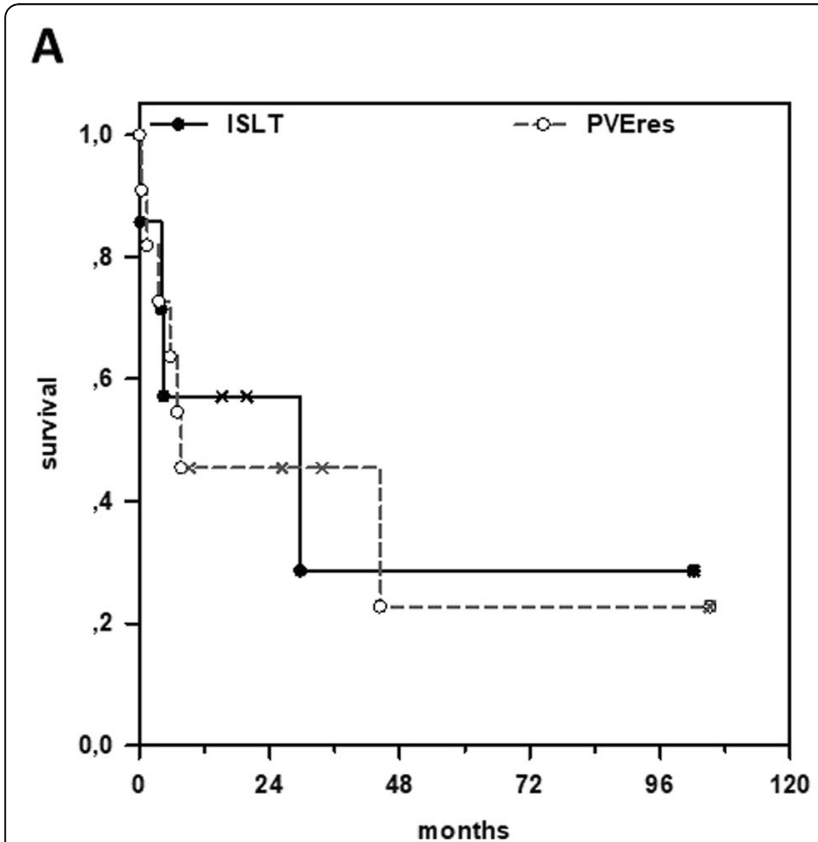

B

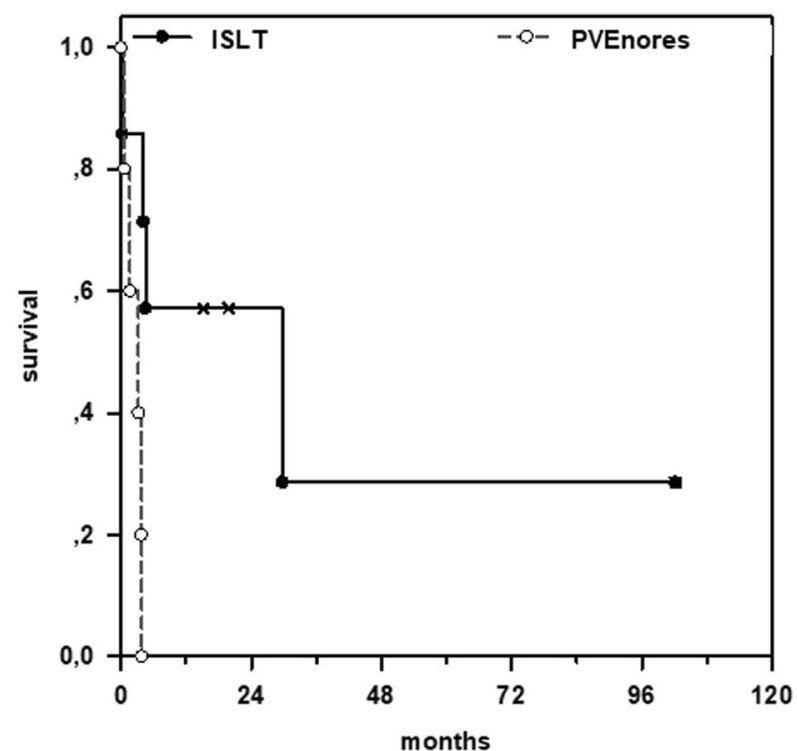

Fig. 3 Survival analysis: a. Kaplan Meier Survial curve demonstrates similar survival in ISLT (PVE + in situ split + resection) and PVEres (PVE + resection) groups. b. ISLT patients show significant longer survival compared to PVEnores (PVE only without resection) patients as demonstrated by Kaplan Meier analysis 
group. PVEnores patients demonstrated a significantly shorter survival with no patient alive beyond 4 months $(p=0.03)$ (Fig. 3b).

Looking at liver function in the clinical course prior PVE, post PVE, and one and two weeks post liver resection, our data did not reveal any statistical differences after ISLT and completion extended right hepatectomy (Fig. 4). Both groups demonstrated a non-significant 5fold increase in bilirubin as a sign for transient liver insufficiency (prior PVE: PVEres $1 \mathrm{mg} / \mathrm{dl} \pm 1.3$, ISLT 0.5 $\mathrm{mg} / \mathrm{dl} \pm$ 0.3; 2 weeks post op: PVEres $\overline{5.8} \mathrm{mg} / \mathrm{dl} \pm 5.7$ ISLT $4 \mathrm{mg} / \mathrm{dl} \pm 4.8$ ) (Fig. 4a). Aspartate aminotransferase levels were slightly increased one week post resection in the PVEres group, but returned almost to normal within two weeks for both groups (Fig. 4b). Both INR and creatinine comparably increased after liver resection one week and two weeks post-op for the two groups (Fig. 4c \& d).

\section{Discussion}

This study represents the largest single-center experience with ISLT performed as salvage procedure subsequent to inefficient one-step PVE of all hepatic segments (I/IV-VIII) except II and III. We have previously presented the novel in situ split liver procedure in three patients subsequent to inefficient PVE [21]. In this follow-up study, we demonstrated a comparable outcome after extended right liver resection subsequent to PVE plus ISLT and immediately subsequent to sufficient PVE respectively.

Commensurability of the two groups was demonstrated by comparable patient characteristics including age distribution, co-morbidity and oncological profiles. Our patient population was more heterogeneous from oncologic indications such as CCC, HCC, NET and CRLM; this is in contrast to a recent single center experience on 5 patients solely with colorectal liver

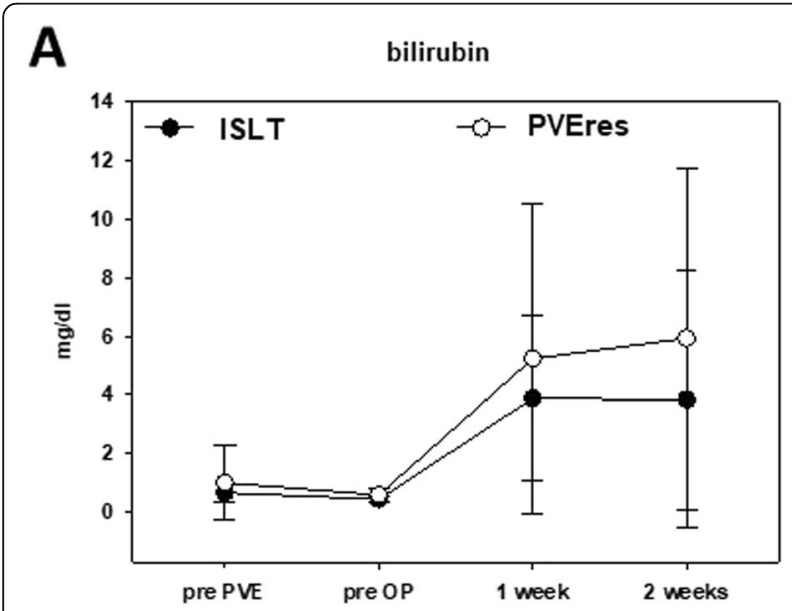

B

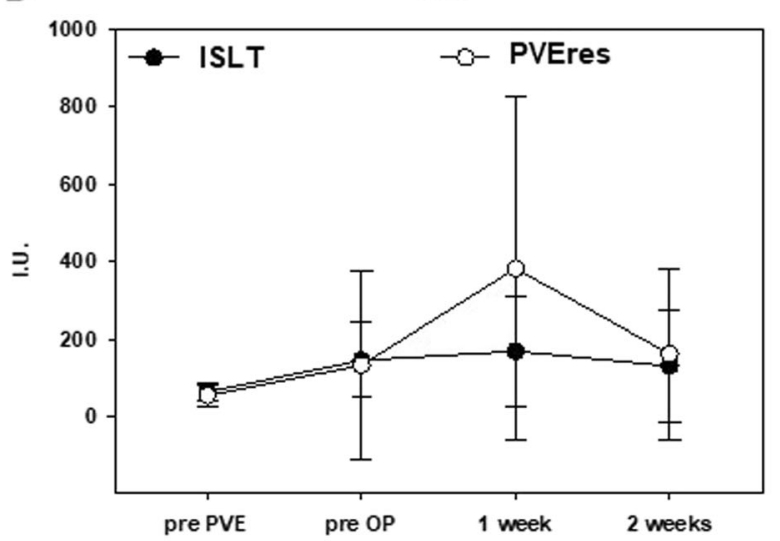

C

INR

D

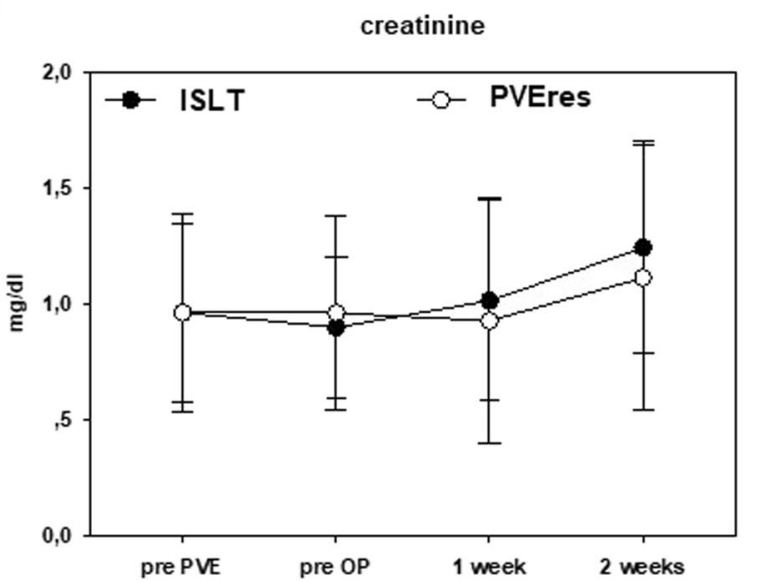

Fig. 4 Mean (s.d.) a. bilirubin, b. glutamate-oxalacetate-transaminase (GOT) and glutamate-pyruvate-transaminase (GPT), c. international normalized ratio (INR) and $\mathbf{d}$. creatinine levels pre PVE, pre operation, 1 week and 2 weeks after resection for ISLT (PVE + in situ split + resection) and PVEres (PVE + resection) patients. I.U.: international units 
metastases (CRLM), who were subjected to rescue ISLT following PVE [4]. This study deviated from our investigation in that only segments V to VIII were embolized. These patients underwent atypical CRLM liver resections in segments I-III in the course of the ISLT surgery (stage 1) and segments IV to VIII in stage 2 surgery, leaving segment I in place. This was also performed in all but one of the 17 patients in the largest series of rescue ISLT subsequent to failed PVE to date reported on a collective derived from an ISLT (ALPPS) database based on 12 hospitals [5]. In this study, PVE was mainly limited to the right portal branch; segment IV was only addressed in one case. Another recent study performed by Ulmer et al demonstrates the largest single-center experience of 9 patients with rescue ALPPS following insufficient hypertrophy after PVE [26]. However, PVE on segment I was not performed in this study either. In our study, we present eight patients with intention to treat subsequent to failed PVE of segments I and IV to VIII. Out of this group, first stage ISLT was followed by second stage extended right hepatectomy (segments I + IV to VIII) in seven cases. Because we have routinely occluded all portal branches to the to-be-resected segments including segment $\mathrm{I}$, which is unique to all previous mentioned studies, we have applied the full potential of PVE with limited residual perfusion of the right side. However, how much influence these portalvenous shunts have on liver growth, needs to be further investigated.

The ISLT procedure is a relatively novel technique, which has evoked a hot debate in the last few years because it is known to be paralleled by high morbidity and mortality rates, especially in patients with primary liver tumors or cirrhosis patients [6, 22, 32-34]. Previous reports suggest that careful patient selection for ISLT is necessary to reduce the mortality $[6,35,36]$. The advantage of ISLT strategies is clearly seen in the high proliferative stimulus that induces hypertrophy of the FLRV at a rate that is unmatched by PVE [17, 37-39]. An inadequate increase in the FLRV after PVE is a challenging and limiting problem which represents an exclusion criteria for extended hepatic resection [2, 3, 34, 40, 41].

The development of left to right portal venous shunting in spite of PVE occlusion has been shown to negatively correlate with FLRV hypertrophy [42, 43]. The improved gain in FLRV subsequent to the ISLT procedures may be a result of the improved isolation of the non-future liver remnant from portal blood supply by transecting the plain for collateral formation along the border of segment IV and segments II /III. Further, sparing segment IV in the course of PVE concepts seems to be associated with compromised levels of FLRV gain [44], which is supported by our observation that PVE with inclusion of segment IV is more effective for increasing the FLRV than open right portal ligation [10]. Although segment IV perfusion via segmental portal branches is not influenced by the ISLT procedure itself, a two-sided isolation of hepatic segment IV - that is the PVE-occluded portal supply from central and collaterals along falciform ligament on the other side - might maximize the FLRV gain after the ISLT. Moreover, it seems advisable to address segment IV during PVE in order to achieve the maximum PVE-effect and to reduce the chance of a failed PVE.

The mean 90-day mortality after extended right resection (stage 2) following ISLT (stage 1) of 14.3\% $(n=1 / 7)$ is in the scope of that reported by others of up to $16 \%$ [35]. Lower rates such as $8.8 \%$ have been reported in series with patients exclusively treated for CRLM [4]. The ALPPS registry did not reveal any morbidity or mortality rates after rescue ISLT [5]. However, our patient collective demonstrated an average age of 67 years; this might be relevant for the interpretation of the herein reported mortality because patient age beyond 60 years is associated with an increased risk for morbidity and mortality due to impaired regenerative potential [45].

For cases of ISLT as a rescue measure, we and others $[4,5,23,26]$ have demonstrated the preserved capacity to gain the FLRV even with previously failed portal occlusion concepts. Even on a small number of patients, we could demonstrate for the first time long-term outcome on patients after ISLT in this single center analysis. We revealed a comparable overall survival after resection in the ISLT group compared with patients resected subsequent to sufficient PVE. Without the option of ISLT, those patients would have been categorized as inoperable. Our survival data demonstrate a survival benefit of ISLT individuals over patients in our program who did not reach eligibility for resective surgery due to inadequate FLRV. All non-resected patients died within 4 months.

The amount of liver growth does not necessarily reflect the liver function, especially in patients with chronic liver diseases. However, markers of hepatic damage, metabolism and syntheses were comparable in the course following extended right resection in insufficient PVE plus ISLT patients and adequate PVE alone individuals respectively. These data suggest that liver function follows volume subsequent to ISLT as a salvage strategy to pre-condition the FLRV after failed PVE.

Obviously, this study has some limitations. Even though we present a large single-center experience of eight patients in this selected patient group, it remains a small heterogenous collective with patients with different tumor entities especially in the ISLT and non-resection groups. However, it was conducted with standardized and uniform PVE and surgical strategies, which was not 
the case in other multicenter studies that have reported on that topic so far $[4,5,23]$. Furthermore, due to the heterogeneity concerning oncological background leading to resective surgery it is very difficult to compare patients, although the resection groups here were comparable among each other to that respect. To overcome some of this limitations, multicentered prospective trials with harmonized interventional and surgical concepts are required to reach an acceptable level of comparability and to draw the right conclusions for clinical practice. Facing a rather infrequent phenomenon of a therapeutic concept, implemented in a limited number of liver resection programs, such a study will be challenging, but vital to accomplish. This kind of study may provide criteria and the decision guidance for the optimal timespan between PVE and making the choice whether to proceed with ISLT or to perform a singlestage extended hepatic resection.

\section{Conclusion}

In summary, our results showed similar liver function and comparable overall survival for patients who underwent a rescue ISLT after inadequate PVE compared to those with immediate extended right hepatectomy subsequent to initially sufficient PVE. We believe that ISLT could be applied earlier after failed PVE because the complication rate is not unfavorable and we could demonstrate a clear survival benefit. Consequently, patients should be re-evaluated 6-8 weeks after PVE, and in cases of inadequate FLRV growth, ISLT can be safely considered as an intermediate step to achieve operability.

\section{Supplementary information}

Supplementary information accompanies this paper at https://doi.org/10. 1186/s12893-020-00721-y.

Additional file 1: Figure 1. Future liver remnant volume (FLRV) gain pre or post PVE. A. PVEres (PVE + resection) patients significantly increased FLRV when compared to PVEnores (PVE only without resection). B. Statistical difference in FLRV to bodyweight ratio within PVEres and PVEnores patients. BW: body weight. FLRV: future liver remnant volume. ml: milliliter. $p<0.05 ;{ }^{* *} p<0.01$; n.s. - not significant

\section{Abbreviations}

ALPPS : Associating Liver Partition and Portal Vein Ligation for Staged Hepatectomy; ASA : American Society of Anesthesiologists; BMI : Body mass index; CCC: Cholangiocellular carcinoma; CRLM: Colorectal liver metastases; CT: Computed tomography; FLRVbw: FLRV to body weight-ratio; FLRV: Future liver remnant volume; HCC: Hepatocellular carcinoma; INR: International normalized ratio; ISLT: In situ split plus portal vein ligation;

PHLF: Posthepatectomy liver failure; POD: Postoperative day; PVE: Portal venous embolization; RCLM: Liver metastases from renal cell carcinoma; TLV: Total liver volumes; TV: Tumor-volume

Acknowledgements

Not applicable.

\section{Authors' contributions}

Study conception, design and overall analysis and interpretation of data, drafting, revising the manuscript (N.L., S.V., S.A., Y.K., J.S.a.E.), Data analysis and interpretation (N.L., S.V., S.A., Y.K., S.A.T., J.S.a.E), manuscript preparation (N.L. S.V., S.A., J.S.a.E.), Data presentation (N.L., J.S.a.E.), conceptual contributions and manuscript revision (L.S., A.L., A.K., H.A., S.A.T., A.R, W.T.K.). All authors have read and approved the manuscript.

\section{Funding}

No funding was obtained for this study.

\section{Availability of data and materials}

The datasets used and/or analyzed during the current study are available from the corresponding author on reasonable request.

\section{Ethics approval and consent to participate}

This study was approved by the local institutional review board (Heinrich Heine University, Duesseldorf, Germany; study-no.: 2018-258-KFogU). All procedures performed in this study were in accordance with the ethical standards in the 1964 Declaration of Helsinki and its later amendments. Informed consent was waived because no data regarding the cases were disclosed.

\section{Consent for publication}

Not applicable.

\section{Competing interests}

The authors declare that they have no competing interests.

\section{Author details}

'Department of Surgery A, University Hospital Duesseldorf, Duesseldorf, Germany. ${ }^{2}$ Department of General, Visceral, Thorax and Pediatric Surgery,Heinrich-Heine-University Hospital, Moorenstr. 5, 40225 Duesseldorf, Germany. ${ }^{3}$ Present address: Center of Visceral Medicine, Department of Visceral Surgery, Protestant Hospital of Bethel Foundation, Bielefeld, Germany. ${ }^{4}$ Department of Diagnostic and Interventional Radiology, University Hospital Duesseldorf, Duesseldorf, Germany. ${ }^{5}$ Present ccaddress: Department of Visceral Surgery and Medicine, University Hospital Bern, University of Bern, Bern, Switzerland. 'Present address: Department of Surgery, Ameos Hospital, Bremerhaven, Germany.

Received: 15 October 2019 Accepted: 23 March 2020

Published online: 06 April 2020

\section{References}

1. Shindoh J, Truty MJ, Aloia TA, Curley SA, Zimmitti G, Huang SY, et al. Kinetic growth rate after portal vein embolization predicts posthepatectomy outcomes: toward zero liver-related mortality in patients with colorectal liver metastases and small future liver remnant. J Am Coll Surg. 2013;216(2): 201-9.

2. Kishi Y, Abdalla EK, Chun YS, Zorzi D, Madoff DC, Wallace MJ, et al. Three hundred and one consecutive extended right hepatectomies: evaluation of outcome based on systematic liver volumetry. Ann Surg. 2009;250(4):540-8.

3. Brouquet A, Andreou A, Shindoh J, Vauthey JN. Methods to improve resectability of hepatocellular carcinoma. Recent Results Cancer Res. 2013; 190:57-67.

4. Sparrelid E, Gilg S, Brismar TB, Lundell L, Isaksson B. Rescue ALPPS is efficient and safe after failed portal vein occlusion in patients with colorectal liver metastases. Langenbeck's Arch Surg. 2017;402(1):69-75.

5. Enne M, Schadde E, Bjornsson B, Hernandez Alejandro R, Steinbruck K, Viana E, et al. ALPPS as a salvage procedure after insufficient future liver remnant hypertrophy following portal vein occlusion. HPB (Oxford). 2017;19(12): 1126-9.

6. Cai $X$, Tong $Y, Y u H$, Liang $X$, Wang $Y$, Liang $Y$, et al. The ALPPS in the treatment of hepatitis B-related hepatocellular carcinoma with cirrhosis: A single-center study and literature review. Surg Innov. 2017;24(4):358-64.

7. Ratti F, Cipriani F, Gagliano A, Catena M, Paganelli M, Aldrighetti L. Defining indications to ALPPS procedure: technical aspects and open issues. Updat Surg. 2014;66(1):41-9.

8. Shindoh J, Vauthey JN, Zimmitti G, Curley SA, Huang SY, Mahvash A, et al. Analysis of the efficacy of portal vein embolization for patients with extensive liver malignancy and very low future liver remnant volume, 
including a comparison with the associating liver partition with portal vein ligation for staged hepatectomy approach. J Am Coll Surg. 2013;217(1):12633 discussion 33-4

9. Makuuchi M, Thai BL, Takayasu K, Takayama T, Kosuge T, Gunven P, et al. Preoperative portal embolization to increase safety of major hepatectomy for hilar bile duct carcinoma: a preliminary report. Surgery. 1990;107(5):521-7.

10. Broering DC, Hillert C, Krupski G, Fischer L, Mueller L, Achilles EG, et al. Portal vein embolization vs. portal vein ligation for induction of hypertrophy of the future liver remnant. J Gastrointest Surg. 2002;6(6):905-13 discussion 13.

11. Turrini O, Ewald J, Viret F, Sarran A, Goncalves A, Delpero JR. Two-stage hepatectomy: who will not jump over the second hurdle? Eur J Surg Oncol. 2012;38(3):266-73.

12. Wicherts DA, de Haas RJ, Andreani P, Sotirov D, Salloum C, Castaing D, et al. Impact of portal vein embolization on long-term survival of patients with primarily unresectable colorectal liver metastases. Br J Surg. 2010;97(2):240-50.

13. Abulkhir A, Limongelli $P$, Healey AJ, Damrah $O$, Tait $P$, Jackson J, et al. Preoperative portal vein embolization for major liver resection: a metaanalysis. Ann Surg. 2008;247(1):49-57.

14. Simoneau E, Aljiffry M, Salman A, Abualhassan N, Cabrera T, Valenti D, et al. Portal vein embolization stimulates tumour growth in patients with colorectal cancer liver metastases. HPB (Oxford). 2012;14(7):461-8.

15. Farges $O$, Belghiti J, Kianmanesh R, Regimbeau JM, Santoro R, Vilgrain V, et al. Portal vein embolization before right hepatectomy: prospective clinical trial. Ann Surg. 2003;237(2):208-17.

16. Schnitzbauer AA, Lang SA, Goessmann H, Nadalin S, Baumgart J, Farkas SA, et al. Right portal vein ligation combined with in situ splitting induces rapid left lateral liver lobe hypertrophy enabling 2-staged extended right hepatic resection in small-for-size settings. Ann Surg. 2012;255(3):405-14.

17. de Santibanes E, Clavien PA. Playing play-Doh to prevent postoperative liver failure: the "ALPPS" approach. Ann Surg. 2012;255(3):415-7.

18. Alvarez FA, Ardiles V, Sanchez Claria R, Pekolj J, de Santibanes E. Associating liver partition and portal vein ligation for staged hepatectomy (ALPPS): tips and tricks. J Gastrointest Surg. 2013;17(4):814-21.

19. Sala S, Ardiles V, Ulla M, Alvarez F, Pekolj J, de Santibanes E. Our initial experience with ALPPS technique: encouraging results. Updat Surg. 2012; 64(3):167-72.

20. de Santibanes E, Alvarez FA, Ardiles V. How to avoid postoperative liver failure: a novel method. World J Surg. 2012:36(1):125-8.

21. Knoefel WT, Gabor I, Rehders A, Alexander A, Krausch M, Schulte am Esch J, et al. In situ liver transection with portal vein ligation for rapid growth of the future liver remnant in two-stage liver resection. Br J Surg. 2013;100(3):388-94.

22. Li J, Girotti P, Konigsrainer I, Ladurner R, Konigsrainer A, Nadalin S. ALPPS in right trisectionectomy: a safe procedure to avoid postoperative liver failure? J Gastrointest Surg. 2013;17(5):956-61.

23. Tschuor C, Croome KP, Sergeant G, Cano V, Schadde E, Ardiles V, et al. Salvage parenchymal liver transection for patients with insufficient volume increase after portal vein occlusion -- an extension of the ALPPS approach. Eur J Surg Oncol. 2013;39(11):1230-5.

24. Bjornsson B, Gasslander T, Sandstrom P. In situ split of the liver when portal venous embolization fails to induce hypertrophy: a report of two cases. Case Rep Surg. 2013;2013:238675.

25. Conrad C, Shivathirthan N, Camerlo A, Strauss C, Gayet B. Laparoscopic portal vein ligation with in situ liver split for failed portal vein embolization. Ann Surg. 2012;256(3):e14-5 author reply e6-7.

26. Ulmer TF, de Jong C, Andert A, Bruners P, Heidenhain CM, Schoening W, et al. ALPPS procedure in insufficient hypertrophy after portal vein embolization (PVE). World J Surg. 2017:41(1):250-7.

27. Dindo D, Demartines N, Clavien PA. Classification of surgical complications: a new proposal with evaluation in a cohort of 6336 patients and results of a survey. Ann Surg. 2004;240(2):205-13.

28. am Esch JS, Schmelzle M, Furst G, Robson SC, Krieg A, Duhme C, et al. Infusion of CD133+ bone marrow-derived stem cells after selective portal vein embolization enhances functional hepatic reserves after extended right hepatectomy: a retrospective single-center study. Ann Surg. 2012;255(1):79-85.

29. Chun YS, Ribero D, Abdalla EK, Madoff DC, Mortenson MM, Wei SH, et al. Comparison of two methods of future liver remnant volume measurement. J Gastrointestinal Surg. 2008;12(1):123-8.

30. Truant S, Oberlin O, Sergent G, Lebuffe G, Gambiez L, Ernst O, et al. Remnant liver volume to body weight ratio $>$ or $=0.5 \%$ : A new cut-off to estimate postoperative risks after extended resection in noncirrhotic liver. Am Coll Surg. 2007;204(1):22-33.
31. Rahbari NN, Garden OJ, Padbury R, Brooke-Smith M, Crawford M, Adam R, et al Posthepatectomy liver failure: a definition and grading by the international study Group of Liver Surgery (ISGLS). Surgery. 2011;149(5):713-24.

32. Eshmuminov D, Raptis DA, Linecker $M$, Wirsching $A$, Lesurtel $M$, Clavien PA. Meta-analysis of associating liver partition with portal vein ligation and portal vein occlusion for two-stage hepatectomy. Br J Surg. 2016;103(13): 1768-82.

33. Truant S, Scatton O, Dokmak S, Regimbeau JM, Lucidi V, Laurent A, et al. Associating liver partition and portal vein ligation for staged hepatectomy (ALPPS): impact of the inter-stages course on morbi-mortality and implications for management. Eur J Surg Oncol. 2015;41(5):674-82.

34. Schadde E, Ardiles V, Slankamenac K, Tschuor C, Sergeant G, Amacker N, et al. ALPPS offers a better chance of complete resection in patients with primarily unresectable liver tumors compared with conventional-staged hepatectomies: results of a multicenter analysis. World J Surg. 2014;38(6):1510-9.

35. Linecker M, Bjornsson B, Stavrou GA, Oldhafer KJ, Lurje G, Neumann U, et al. Risk adjustment in ALPPS is associated with a dramatic decrease in early mortality and morbidity. Ann Surg. 2017;266(5):779-86.

36. Schadde E, Raptis DA, Schnitzbauer AA, Ardiles V, Tschuor C, Lesurtel M, et al. Prediction of mortality after ALPPS Stage-1: an analysis of 320 patients from the international ALPPS registry. Ann Surg. 2015;262(5):780-5 discussion 5-6.

37. Chia NH, Lai EC, Lau WY. Associating liver partition and portal vein ligation for a patient with hepatocellular carcinoma with a background of hepatitis B related fibrotic liver. Int J Surg Case Rep. 2014;5(12):1077-81.

38. Torres OJ, Moraes-Junior JM. Lima e Lima NC, Moraes AM. Associating liver partition and portal vein ligation for staged hepatectomy (ALPPS): a new approach in liver resections. Arq Bras Cir Dig. 2012;25(4):290-2.

39. Govil S. Rapid improvement in liver volume induced by portal vein ligation and staged hepatectomy: the ALPPS procedure. HPB (Oxford). 2012;14(12):874.

40. Truty MJ, Vauthey JN. Uses and limitations of portal vein embolization for improving perioperative outcomes in hepatocellular carcinoma. Semin Oncol. 2010;37(2):102-9.

41. Giraudo G, Greget M, Oussoultzoglou E, Rosso E, Bachellier P, Jaeck D. Preoperative contralateral portal vein embolization before major hepatic resection is a safe and efficient procedure: a large single institution experience. Surgery. 2008;143(4):476-82.

42. Zeile M, Bakal A, Volkmer JE, Stavrou GA, Dautel P, Hoeltje J, et al. Identification of cofactors influencing hypertrophy of the future liver remnant after portal vein embolization-the effect of collaterals on embolized liver volume. Br J Radiol. 2016;89(1068):20160306.

43. Yokoyama $Y$, Nagino M, Nimura Y. Mechanisms of hepatic regeneration following portal vein embolization and partial hepatectomy: a review. World J Surg. 2007:31(2):367-74.

44. Kishi Y, Madoff DC, Abdalla EK, Palavecino M, Ribero D, Chun YS, et al. Is embolization of segment 4 portal veins before extended right hepatectomy justified? Surgery. 2008;144(5):744-51.

45. Vennarecci G, Ferraro D, Tudisco A, Levi Sandri GB, Guglielmo N, Berardi G et al. The ALPPS procedure: hepatocellular carcinoma as a main indication. An Italian single-center experience. Updat Surg. 2019;71(1):67-75.

\section{Publisher's Note}

Springer Nature remains neutral with regard to jurisdictional claims in published maps and institutional affiliations.

Ready to submit your research? Choose BMC and benefit from:

- fast, convenient online submission

- thorough peer review by experienced researchers in your field

- rapid publication on acceptance

- support for research data, including large and complex data types

- gold Open Access which fosters wider collaboration and increased citations

- maximum visibility for your research: over $100 \mathrm{M}$ website views per year

At BMC, research is always in progress.

Learn more biomedcentral.com/submission 